\title{
Luteolin inhibits progestin-dependent angiogenesis, stem cell-like characteristics, and growth of human breast cancer xenografts
}

\author{
Matthew T. Cook ${ }^{1,2}$, Yayun Liang ${ }^{1,2}$, Cynthia Besch-Williford ${ }^{3}$, Sandy Goyette ${ }^{1,2}$, Benford Mafuvadze ${ }^{1,2}$ \\ and Salman M. Hyder ${ }^{1,2^{*}}$
}

*Correspondence:

hyders@missouri.edu

2 Dalton Cardiovascular

Research Center, University

of Missouri, 134 Research

Park Drive, Columbia, $\mathrm{MO}$

65211, USA

Full list of author information

is available at the end of the article

\begin{abstract}
Purpose: Clinical trials and epidemiological evidence have shown that combined estrogen/progestin hormone replacement therapy, but not estrogen therapy alone, increases breast cancer risk in post-menopausal women. Previously we have shown that natural and synthetic progestins, including the widely used synthetic progestin medroxyprogesterone acetate (MPA), increase production of a potent angiogenic factor, vascular endothelial growth factor (VEGF), in human breast cancer cells, potentially providing an explanation for progestin's mechanism of action. Here, we tested the effects of luteolin (LU), a flavonoid commonly found in fruits and vegetables, on inhibiting progestin-dependent VEGF induction and angiogenesis in human breast cancer cells, inhibiting stem cell-like characteristics, as well as breast cancer cell xenograft tumor growth in vivo and expression of angiogenesis markers.

Methods: Viability of both T47-D and BT-474 cells was measured using sulforhodamine B assays. Enzyme-linked immunosorbent assays were used to monitor VEGF secretion from breast cancer cells. Progestin-dependent xenograft tumor growth was used to determine LU effects in vivo. CD31 immunohistochemistry was used to determine blood-vessel density in xenograft tumors. CD44 expression, aldehyde dehydrogenase activity, and mammosphere-formation assays were used to monitor stem cell-like characteristics of breast cancer cells.
\end{abstract}

Results: Luteolin treatment reduced breast cancer cell viability, progestin-dependent VEGF secretion from breast cancer cells, and growth of MPA-dependent human breast cancer cell xenograft tumors in nude mice. LU treatment also decreased xenograft tumor VEGF expression and blood-vessel density. Furthermore, LU blocked MPAinduced acquisition of stem cell-like properties by breast cancer cells.

Conclusions: Luteolin effectively blocks progestin-dependent human breast cancer tumor growth and the stem cell-like phenotype in human breast cancer cells.

Keywords: Luteolin, Breast cancer, Tumor growth, Medroxyprogesterone acetate, Therapeutic

\section{Springer}

(C) 2015 Cook et al. This article is distributed under the terms of the Creative Commons Attribution 4.0 International License (http:// creativecommons.org/licenses/by/4.0/), which permits unrestricted use, distribution, and reproduction in any medium, provided you give appropriate credit to the original author(s) and the source, provide a link to the Creative Commons license, and indicate if changes were made. 


\section{Background}

Breast cancer is the most commonly diagnosed form of cancer and the second-leading cause of cancer-related death in American women. In 2015, an estimated 232,000 new cases of breast cancer will be diagnosed, with approximately 40,000 deaths (Siegel et al. 2015). A subset of both newly diagnosed cases and breast cancer-related deaths is linked to the use of hormone replacement therapy (HRT) containing a combination of estrogen and progestin in post-menopausal women (Ross et al. 2000; Chlebowski et al. 2003). A progestin component is administered to women with an intact uterus to prevent endometrial cancer; however, its inclusion in the HRT formulation has been found to increase the incidence of breast cancer significantly compared with that in post-menopausal women undergoing HRT containing estrogen alone (Ross et al. 2000; Chlebowski et al. 2003; Writing Group for the Women's Health Initiative Investigators 2002). The increased risk of breast cancer is greatly reduced after progestin use ceases, correlating with a $7 \%$ decline in breast cancer incidence after the results of the WHI trial were announced (Siegel et al. 2015; Writing Group for the Women's Health Initiative Investigators 2002; Tsai et al. 2011). Although the use of HRT has become increasingly controversial, in the United States an estimated 1.6 million women take combined estrogen/ progestin HRT to alleviate the symptoms of menopause (Tsai et al. 2011).

Studies from our laboratory and others have shown that progestins promote the development of hormone-responsive breast cancers by increasing the production of vascular endothelial growth factor (VEGF). This in turn increases neovascularization, cell proliferation, and metastasis (Folkman 1995; Hanahan and Folkman 1996; Liang and Hyder 2005; Liang et al. 2010). The synthetic anti-progestin RU-486, which acts by blocking the progesterone receptor (PR), inhibits progestin-dependent tumor growth, indicating that the process is dependent on PR. We also have shown that progestins stimulate breast cancer metastasis to lymph nodes in an animal model, a phenomenon that has recently been confirmed in human subjects (Liang et al. 2010; Chlebowski et al. 2009). Due to the rapid onset of HRT-driven tumors and the similarities between metastatic cancer cells and stem cell-like cells, it has been suggested that latent cells that are not normally exposed to progestins are revitalized by exogenous progestin (Hyder et al. 1998; Horwitz and Sartorius 2008; Brisken 2013). This stimulation causes increased proliferation and leads ultimately to a more aggressive phenotype (Liang and Hyder 2005; Liang et al. 2010). In support of this concept, progestins have been shown to enrich the stem celllike cancer cell population in vitro by dedifferentiating progenitor cells back to a stem cell-like origin (Horwitz and Sartorius 2008; Brisken 2013). Thus, progestins appear to promote breast cancer not only by increasing production of the potent mitogenic factor VEGF and stimulating tumor and endothelial cell proliferation (Liang and Hyder 2005), but also by enriching the stem cell-like population, thereby enabling tumors to grow and metastasize (Liang et al. 2010; Horwitz et al. 2013).

Most synthetic ligands with anti-progestin properties are toxic and cross-react with other steroid receptors, preventing their long-term use (Horwitz 1992). In contrast, the majority of naturally occurring compounds are non-toxic. We therefore undertook studies to identify natural compounds with anti-progestin-like activities that might be used to counter the pro-tumor effects of progestins. Luteolin (LU), a flavonoid that is found in more than 300 plant species (many of which are readily available in the human diet), has 
recently been shown to inhibit a variety of cancers, both in vitro and in vivo, with little to minimal toxicity (Seelinger et al. 2008). Previously we have shown that LU prevents and delays medroxyprogesterone acetate (MPA)-dependent tumor development in the 7,12-dimethylbenz(A)anthracene-induced tumor model, and we proposed that LU possesses long-lasting anti-cancer effects (manuscript under review). In the present study, we conducted studies in a xenograft model to determine whether LU might also be used to treat progestin-dependent breast cancer (Liang et al. 2007). Herein we demonstrate that LU effectively blocks the growth of progestin-dependent human xenograft tumors, inhibits angiogenesis, and restricts the conversion of breast cancer cells into stem celllike cells.

\section{Methods}

Reagents

Luteolin (2-(3,4-dihydroxyphenyl)-5,7-dihydroxy-4H-1-benzopyran-4-one) (LU) was purchased from Tocris (Minneapolis, MN, USA) and dissolved in sterile filtered dimethyl sulfoxide (DMSO; Sigma-Aldrich; St. Louis, MO, USA). Medroxyprogesterone acetate (MPA), progesterone, norethindrone, norgestrel, and RU-486 were purchased from Sigma-Aldrich. Pierce bicinchoninic acid protein reagents were obtained from Fisher Scientific (Pittsburgh, PA, USA). 17- $\beta$ estradiol (E2; $1.7 \mathrm{mg}$ ), MPA (10 mg), and placebo 60-day release pellets were obtained from Innovative Research of America (Sarasota, FL, USA).

\section{Cell lines and culture}

Hormone-responsive BT-474 and T47-D human breast cancer cell lines were obtained from the American Type Culture Collection (Manassas, VA, USA) and maintained at $37^{\circ} \mathrm{C}$ in phenol red-free DMEM/F12 medium (Invitrogen, Waltham, MA, USA) supplemented with $10 \%$ fetal bovine serum (FBS; Sigma-Aldrich) in a humidified atmosphere of $5 \% \mathrm{CO}_{2}$. For all in vitro experiments, cells were maintained in DMEM/F12 supplemented with $5 \%$ dextran-coated charcoal (DCC)-stripped FBS for $24 \mathrm{~h}$ prior to treatment. Subsequently, cells were washed and further incubated in fresh $5 \%$ DCC-stripped FBS-DMEM/F12.

\section{Cell viability assay}

Viable cells were quantitated using sulforhodamine B (SRB) assays (Skehan et al. 1990). In brief, breast cancer cells in $100 \mu \mathrm{l}$ DMEM/F12/10 \% FBS medium were seeded into each well of a 96-well plate and incubated at $37{ }^{\circ} \mathrm{C}$ overnight in $5 \% \mathrm{CO}_{2}$. Cells were treated (in six replicates) with either LU or DMSO (controls) in DMEM/5 \% FBS for periods up to $48 \mathrm{~h}$, then subjected to SRB assays.

\section{Apoptosis assay}

Apoptosis was evaluated by staining with Annexin V-fluorescein isothiocyanate (FITC) and propidium iodide (PI) as described previously (Liang et al. 2006). T47-D cells were grown to 50-60 \% confluence in DMEM/F12/10 \% FBS, at which point the media was switched to $5 \%$ DCC-stripped FBS-DMEM/F12. After $24 \mathrm{~h}$, cells were treated with LU \pm MPA for an additional $16 \mathrm{~h}$. Treated cells were harvested using $0.05 \%$ 
trypsin-EDTA, stained, and subjected for fluorescence-activated cell sorting (FACS) analysis per the manufacturer's protocol (BioVision Inc, Milpitas, CA, USA).

\section{VEGF enzyme-linked immunosorbent assay (ELISA)}

The Quantikine human VEGF ELISA kit was purchased from R\&D Systems, Inc. (Minneapolis, MN, USA). Supernatant from treated cells was collected and VEGF concentrations measured according to the manufacturer's protocol. Experiments were performed in triplicate, and each sample was analyzed in duplicate on a microplate reader. Interand intra-assay coefficients of variance given by the manufacturer for cell culture supernatant assays are 5-8.5 and 3.5-6.5\%, respectively.

\section{Bicinchoninic acid protein assay}

Cells were harvested and pellets resuspended in $300 \mu \mathrm{l}$ lysis buffer $(50 \mathrm{mM}$ Tris/HCl, $\mathrm{pH} 8,150 \mathrm{mM} \mathrm{NaCl}$, and $1 \%$ Nonidet P-40). Protein concentration was determined by measuring absorbance at $562 \mathrm{~nm}$ on a microplate reader, using bovine serum albumin (Thermo Fisher Scientific; Waltham, MA, USA) as standard. Experiments were performed in triplicate, and samples were analyzed in duplicate.

\section{Reverse transcription-polymerase chain reaction (RT-PCR)}

RNA from progestin-treated cells was purified and RT-PCR conducted as described previously (Mafuvadze et al. 2010). The primers used were:

VEGF

F $\quad 5^{\prime}$-CTGCTGTCTTGGGTGCATTGG

R 5 '-CACCGCCTCGGCTTGTCACAT

Glyceraldehyde phosphate dehydrogenase (GAPDH)

F $\quad 5^{\prime}$-ATGAGA AGTATGACAGCC

R $\quad 5^{\prime}$-TGAGTCCTTCCACGATACC

\section{FACS analyses}

For all FACS analysis, treated breast cancer cells were harvested using Accutase (BD Biosciences; San Jose, CA, USA) in place of trypsin-EDTA. Cells $\left(1 \times 10^{6}\right)$ were then suspended in $100 \mu \mathrm{l}$ staining buffer and placed in microcentrifuge tubes.

Phycoerythrin (PE)-conjugated mouse anti-human CD24 (20 $\mu$ l) and allophycocyanin (APC)-conjugated mouse anti-human CD44 $(20 \mu \mathrm{l})$ antibodies (both from BD Biosciences) were added to each sample, along with the necessary FACS dye controls, and the samples incubated on ice for $45 \mathrm{~min}$. Cells were washed twice in staining buffer, resuspended in $500 \mu \mathrm{l}$ staining buffer and $1 \mu \mathrm{l}$ of $250 \mu \mathrm{g} / \mathrm{ml}$ PI, and subjected to FACS analysis.

Aldehyde dehydrogenase (ALDH) activity was assessed using the ALDEFLUOR kit (STEMCELL Technologies Inc.; Vancouver, BC, Canada), according to the manufacturer's protocol. All samples were processed within $15 \mathrm{~min}$ of the final wash. Cells were visualized using a Beckman Coulter CyAn ADP FACS machine running Summit 5.2 software and results analyzed as previously described (Ginestier et al. 2007). 


\section{Mammosphere-formation assay}

T47-D cells were grown in $10 \%$ FBS DMEM/F12 medium, then cultured in 5 \% DCCstripped FBS-DMEM/F12 medium for $24 \mathrm{~h}$. Cells were then treated for $48 \mathrm{~h}$ with indicated agent(s) of interest. Cells from each group were subsequently seeded into six-well plates (5000 cells/well) in Complete MammoCult medium (STEMCELL Technologies Inc.) and treatment continued for six more days. Culture medium $(1 \mathrm{ml})$ was refreshed on days 2, 4, and 6 to ensure drug availability. Light microscopy $(10 \times)$ pictures of mammospheres formed were captured after 7 days using an EVOS light microscope. Mammospheres $\geq 60 \mu \mathrm{m}$ in diameter (determined by size exclusion) were counted.

\section{Human breast cancer cell xenograft studies}

Xenograft experiments were performed as described previously (Liang et al. 2007). All facilities were approved by the American Association for Accreditation of Laboratory Animal Care in accordance with current federal regulations and standards. In brief, an E2 60-day release pellet $(1.7 \mathrm{mg})$ was implanted in each nude mouse. Two days later, T47-D cells were suspended in DMEM/F12 medium and injected subcutaneously $\left(1 \times 10^{7}\right.$ cells per $\left.150 \mu \mathrm{l}\right)$ into each flank of nude mouse $(\mathrm{n}=2-4$ animals/group). Mice were then implanted with a 60-day release MPA $(10 \mathrm{mg})$ or placebo pellet 10 days after breast cancer cell injection. When tumors reached about $60 \mathrm{~mm}^{3}$, intraperitoneal treatment with LU (20 mg/kg/day) or vehicle commenced. LU was administered daily for 2 days (loading dose), then every other day until day 79.

\section{Immunohistochemical analyses}

Xenograft tumor-bearing mice were sacrificed at day 79 and tumors collected and processed for immunohistochemical analysis as previously described (Liang et al. 2007). Tumors were collected from both flanks of each mouse and at least three tumors per group were collected for analysis. One section from each individual tumor was subjected to immunohistochemical staining using anti-VEGF (1:100 dilution; Santa Cruz Biotechnology; Dallas, TX, USA), anti-PR, or anti-CD31 polyclonal antibodies, both at 1:50 dilution (DAKO; Carpinteria, CA, USA).

Four random fields were captured from every stained section to minimize errors due to differences in cellularity. Regions of staining within tumors were recorded. Fovea Pro 3.0 software (Reindeer Graphics; Ashville, NC, USA) was used to quantitate the percent area of VEGF staining, while the percent of PR-positively stained cells was calculated using the color threshold in Image $\mathrm{J}(\mathrm{NIH})$. This facilitated precise discrimination between positive/negative cells and background. For quantitating blood vessels, five CD31-labeled 10x sections were taken from each tumor to minimize intra-tumoral variation (Liang et al. 2007). The total number of vessels was counted in each section and then averaged per corresponding tumor.

Immunohistochemical staining data were reported as mean \pm standard error of the mean (SEM) per treatment group, with each group having an $\mathrm{n} \geq 3$ tumors analyzed.

\section{Statistical analysis}

Statistical significance was tested using one-way analysis of variance (ANOVA) followed by a Newman-Keuls multiple comparison test to determine the difference in mean 
between groups. A two-way repeated measures ANOVA was used for animal weights. If normality failed, the data were tested using a nonparametric one-way ANOVA on ranks (Kruskal-Wallis), followed by Newman-Keuls comparison test. Data were reported as mean \pm SEM. For all comparisons, $P \leq 0.05$ was regarded as statistically significant. Analyses were performed using SigmaPlot 12.5 software.

\section{Results}

\section{Luteolin reduces viability of human breast cancer cells}

When two estrogen receptor- and PR-positive human breast cancer cell lines (BT-474 and T47-D) were exposed for 24 or $48 \mathrm{~h}$ to varying concentrations of LU (0-100 $\mu \mathrm{M})$ used in previous studies (Seelinger et al. 2008), LU markedly reduced cell viability in both a time- and dose-dependent manner (Fig. 1a, b). Following 24-h exposure, LU exhibited an $\mathrm{IC}_{50}$ value of approximately $50 \mu \mathrm{M}$ against these cells, with minimal or no effect observed at $10 \mu \mathrm{M}$ during the same treatment period. Thus, unless otherwise stated, subsequent experiments were conducted with $10 \mu \mathrm{M}$ LU for $16-18 \mathrm{~h}$ in order to determine the biological effects of LU without inducing loss of cell viability and cell death.
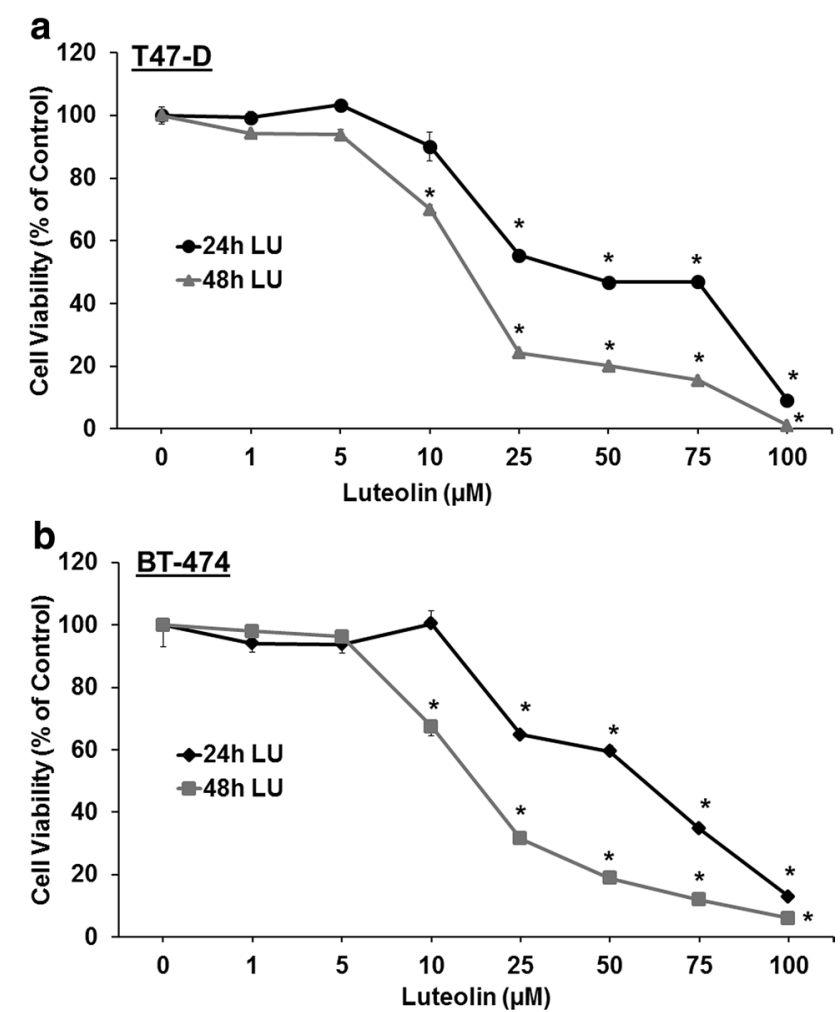

Fig. 1 Luteolin reduces human breast cancer cell viability. T47-D (a) and BT-474 (b) breast cancer cells were seeded overnight in a 96-well plate $\left(0.5 \times 10^{4}\right.$ cells/well and $1 \times 10^{4}$ cells/well, respectively). Cells were then washed and treated with the indicated concentration of luteolin (LU) for either 24 or $48 \mathrm{~h}$. Cell viability was determined using SRB assays. Results represent mean \pm SEM ( $n=3$, in six replicates). *Significantly different from control (DMSO only) $(P<0.05$, ANOVA) 


\section{Luteolin inhibits progestin-induced VEGF secretion from breast cancer cells}

We have previously established that both natural and synthetic progestins induce synthesis and secretion of the potent angiogenic factor VEGF from both T47-D and BT-474 cells (Liang and Hyder 2005; Hyder et al. 1998). To examine LU's ability to block progestin-induced secretion of VEGF from breast cancer cells, T47-D cells were treated for $18 \mathrm{~h}$ with MPA, both with and without LU or RU-486, then release of VEGF into the culture medium measured. Treatment with MPA significantly increased VEGF secretion. Levels of MPA-dependent VEGF secretion were significantly reduced by $10 \mu \mathrm{M} \mathrm{LU}$; however, $2 \mu \mathrm{M}$ LU had no effect (Fig. 2a). Similarly, $10 \mu \mathrm{M}$ LU lowered VEGF secretion in response to both progesterone and two commonly used synthetic progestins, norethindrone and norgestrel (Fig. 2b). Importantly, LU alone did not induce VEGF, therefore behaving in a similar fashion to RU-486 (Fig. 2a).

When we examined whether LU exerted similar effects in other breast cancer cells, we found that LU $(10 \mu \mathrm{M})$ also significantly reduced levels of MPA-induced VEGF secretion in BT-474 cells. At higher concentrations $(25 \mu \mathrm{M})$, LU blocked even basal levels of VEGF secretion (Fig. 2c).

\section{Luteolin suppresses progestin-induced VEGF mRNA expression in breast cancer cells}

When T47-D cells were used to determine whether LU suppressed progestin-induced VEGF at the mRNA level, MPA induced VEGF mRNA isoforms, while LU and RU-486 both suppressed MPA-induced VEGF mRNA expression. Neither LU nor RU-486 alone induced VEGF mRNA expression (Fig. 3).

\section{Luteolin induces apoptosis in breast cancer cells}

When T47-D cells were used to determine whether LU induced breast cancer cell apoptosis, $50 \mu \mathrm{M}$ LU induced apoptosis whether or not MPA was present (Fig. 4), indicating that MPA was unable to protect breast cancer cells from LU-induced cell death.

\section{Luteolin inhibits MPA-induced breast cancer cell xenograft tumor growth in vivo}

We next studied LU's therapeutic effect in a progestin-dependent T47-D xenograft tumor model previously developed in our laboratory (Liang et al. 2007). The experimental protocol is shown in Fig. 5a. LU blocked progestin-induced T47-D tumor growth; tumor volumes in LU-treated animals decreased to those of control animals by day 76 (Fig. 5b). No LU-related toxicity was observed in any of the experimental animals, as determined by animal weight (Fig. 5c). In addition, animal behavior (i.e., eating, grooming, and mobility) was no different in LU-treated mice, further suggesting that LU had little to no toxicity.

\section{Luteolin reduces expression of angiogenesis markers in breast cancer cell xenograft tumors}

We have previously shown that progestins increase tumor burden by inducing the angiogenic factor VEGF, suggesting that the tumor growth observed in those studies was most likely due to increased angiogenesis (Liang et al. 2007, 2010). In the present study, when our xenograft model was used to examine the ability of LU to block MPA-driven VEGF induction, tumor VEGF expression was significantly reduced in MPA + LU-treated 

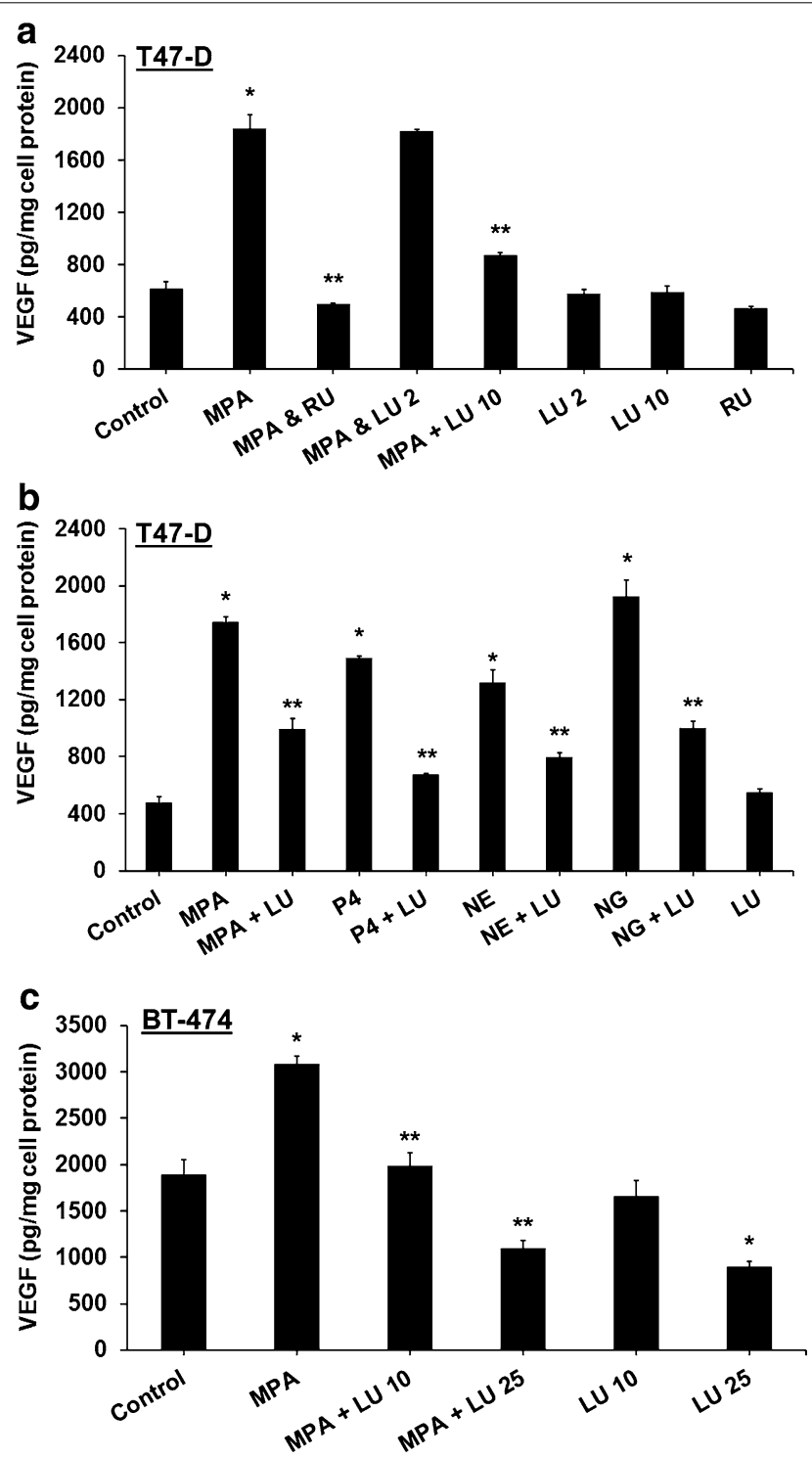

Fig. 2 Luteolin inhibits progestin-induced secretion of VEGF from human breast cancer cells. a T47-D cells were treated at $37^{\circ} \mathrm{C}$ for $18 \mathrm{~h}$ with $10 \mathrm{nM} \mathrm{MPA}, 10 \mathrm{nM} \mathrm{MPA}+1 \mu \mathrm{M} \mathrm{RU}-486$ (RU), $10 \mathrm{nM} \mathrm{MPA}+2$ or $10 \mu \mathrm{M}$ luteolin (LU), $2 \mu \mathrm{M}$ or $10 \mu \mathrm{M} \mathrm{LU}$, or $1 \mu \mathrm{M}$ RU-486. b T47-D cells were treated at $37^{\circ} \mathrm{C}$ for $18 \mathrm{~h}$ with $10 \mathrm{nM} \mathrm{MPA}$, progesterone (P4), norethindrone (NE), or norgestrel (NG) $\pm 10 \mu \mathrm{M} \mathrm{LU}$, or $10 \mu \mathrm{M} \mathrm{LU}$ alone. c BT-474 cells were treated at $37^{\circ} \mathrm{C}$ for $18 \mathrm{~h}$ with $10 \mathrm{nM} \mathrm{MPA} \pm 10$ or $25 \mu \mathrm{M} \mathrm{LU}$, or $10 \mu \mathrm{M}$ or $25 \mu \mathrm{M} \mathrm{LU}$ alone. Levels of VEGF in culture medium were measured by ELISA. In all experiments, LU or RU was administered 30 min prior to MPA. VEGF ELISA values were normalized to cellular protein content, measured using bicinchoninic acid protein assays. Results represent mean $\pm \operatorname{SEM}(n=3$, in duplicate). * Significantly different from control (DMSO only) $(P<0.05$, ANOVA $) .{ }^{*}$ Significantly different from progestin alone $(P<0.05$, ANOVA $)$

animals compared with animals given MPA alone (Fig. 6a). Similarly, animals treated with MPA + LU demonstrated significantly reduced tumor blood-vessel density compared with animals administered MPA alone (Fig. 6b).

\section{Luteolin does not prevent MPA-induced loss of PR in breast cancer cell xenograft tumors}

Xenograft tumor tissues demonstrated an almost complete loss of PR in animals given MPA alone, concurring with previous reports that this represents an active PR function 


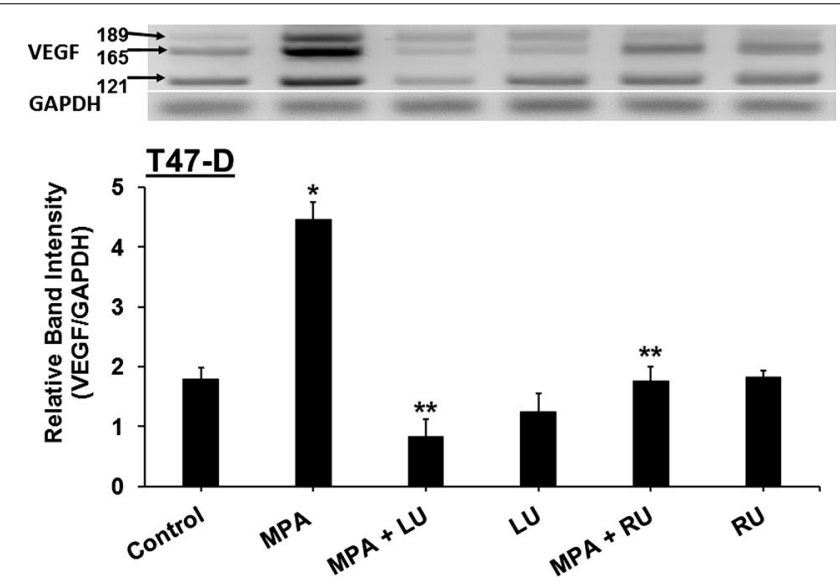

Fig. 3 Luteolin inhibits MPA-induced VEGF mRNA expression in T47-D breast cancer cells. T47-D cells were treated at $37^{\circ} \mathrm{C}$ for $6 \mathrm{~h}$ with $10 \mathrm{nM} \mathrm{MPA} \pm 25 \mu \mathrm{M}$ luteolin (LU) or $1 \mu \mathrm{M}$ RU-486 (RU), or $25 \mu \mathrm{M}$ LU or $1 \mu \mathrm{M}$ RU-486 alone, after which RNA was isolated and RT-PCR for VEGF isoforms performed. Upper panel Representative figure of PCR-amplified VEGF products, showing VEGF 189, 165, and $121 \mathrm{bp}$ bands and the GAPDH band used for normalization. Lower panel Results represent mean band intensities (VEGF/GAPDH) \pm SEM $(n=3) .{ }^{*}$ Significantly different from control (DMSO only) $(P<0.001$, ANOVA). **Significantly different from MPA $(P<0.001$, ANOVA $)$

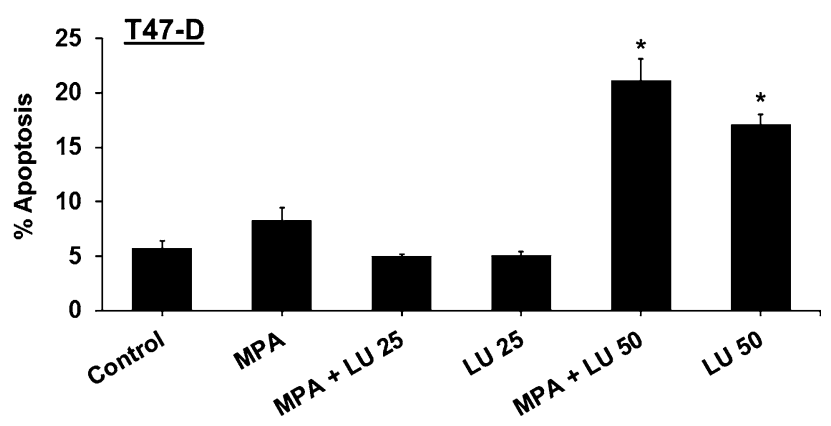

Fig. 4 Luteolin induces apoptosis in breast cancer cells. T47-D cells were treated with $10 \mathrm{nM}$ MPA \pm 25 or $50 \mu \mathrm{M}$ luteolin (LU), or 25 or $50 \mu \mathrm{M} \mathrm{LU}$ alone at $37^{\circ} \mathrm{C}$ for $16 \mathrm{~h}$. Cells were stained with Annexin V-FITC and PI and analyzed by FACS. Results represent mean \pm SEM $(n=3)$. *Significantly different from control (DMSO only) $(P<0.001$, ANOVA)

(Knutson and Lange 2014). LU treatment did not prevent the MPA-induced loss of PR in xenograft tumors (Fig. 6c), suggesting that it does not block PR activation, but rather acts at a point beyond the PR activation step or exerts other post-transcriptional effects on VEGF mRNA or protein. The inability of LU to rescue PR expression was verified by Western-blot analysis of tumor cells in vitro, in which MPA was again shown to lower PR protein expression, whether LU was present or not (data not shown).

\section{Luteolin inhibits MPA-induced stem cell-like properties of breast cancer cells}

We have previously shown that MPA stimulates in vivo tumor cell growth, a phenomenon that is likely linked to its ability to enrich the stem cell-like properties in a small subportion of tumor cells (Hyder et al. 1998; Horwitz and Sartorius 2008). In this study, we examined LU effects on MPA-induced acquisition of stem cell-like properties of breast cancer cells using three indicators of the stem-cell phenotype. First, FACS 


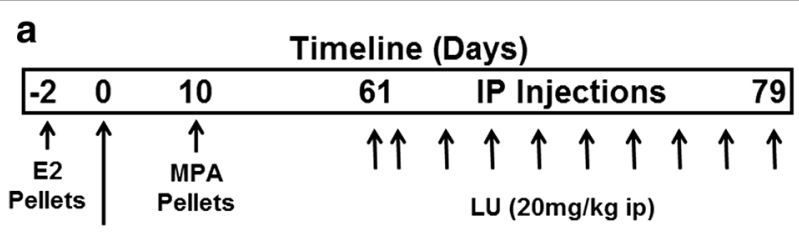

T47-D Inoculate

b
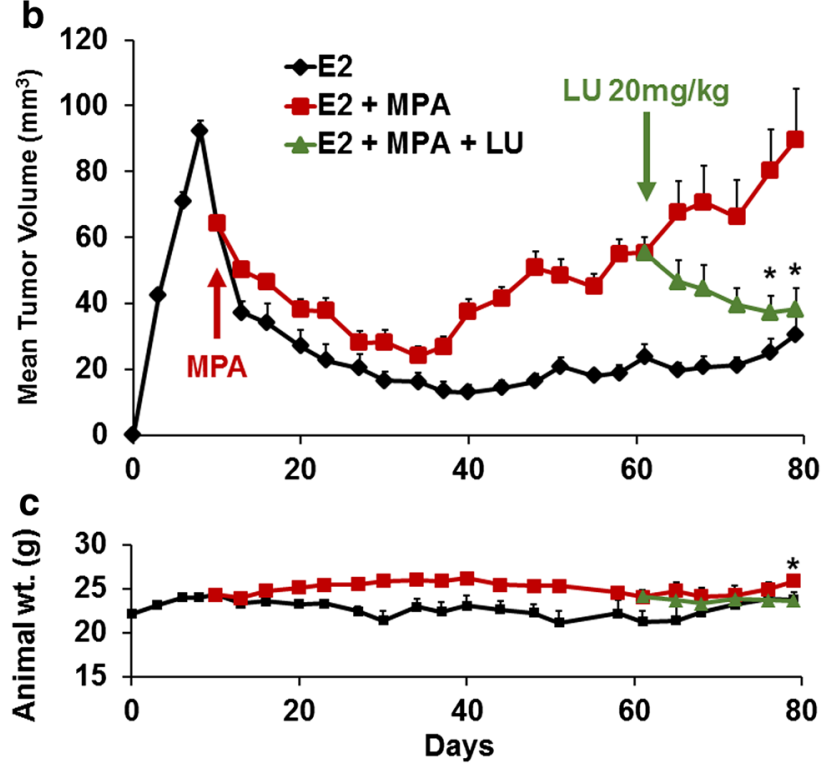

Fig. 5 Luteolin suppresses in vivo growth of MPA-accelerated human T47-D breast cancer cells in a xenograft model. a Protocol for xenograft tumor growth and treatment. An estradiol (E2) pellet was implanted in nude mice and, 2 days later, T47-D cells $\left(1 \times 10^{7}\right)$ were injected subcutaneously into each flank of nude mouse. MPA (10 mg) or placebo pellets were implanted on day 10 . When tumors reached approximately $60 \mathrm{~mm}^{3}$, treatment with luteolin (LU) $(20 \mathrm{mg} / \mathrm{kg}$ ) or vehicle began (arrow day 61). LU was injected intraperitoneal (ip) daily for 2 days (loading dose), followed by injections every other day until day 79. b Luteolin suppresses xenograft tumor growth in vivo. Mice were palpated and tumors measured every other day, and tumor volumes calculated as described (Liang et al. 2007). Results represent mean tumor volumes \pm SEM [E2 group (E2 pellet + vehicle), $n=3$ tumors; $E 2+$ MPA group (MPA pellet + vehicle), $n=7$ tumors; $E 2+M P A+L U$ group (MPA pellet $+L U), n=8$ tumors]. *Significantly different from MPA $(P<0.05$, ANOVA). $\mathbf{c}$ Luteolin does not affect animal weights throughout the experiment. Animals were weighed twice weekly. Results represent mean weights $\pm \mathrm{SEM}$. *Significantly different from E2 $(P<0.05$, ANOVA)

analysis of CD44, a well-recognized marker of breast cancer stem cells, demonstrated that MPA induced a large and highly reproducible CD44 ${ }^{+}$shift in T47-D cells, suggesting that MPA induces an increase in stem cell- or progenitor-like cells, as previously shown (Horwitz and Sartorius 2008; Al-Hajj et al. 2003; Axlund and Sartorius 2012). The MPA-induced increase in the $\mathrm{CD} 44^{+}$population was significantly reduced by exposure to either $25 \mu \mathrm{M}$ LU or $1 \mu \mathrm{M}$ RU-486 (Fig. 7a). The LU effects on MPA induction of CD44 were dose-dependent, given that $25 \mu \mathrm{M} L U$ + MPA but not $10 \mu \mathrm{M} \mathrm{LU}+$ MPA significantly decreased the MPA-induced increase in the $\mathrm{CD} 44^{+}$population (Fig. $7 \mathrm{a}$ ).

Next, MPA induced a significant increase in $\mathrm{ALDH}^{\text {bright }}$ activity, which is another established stem-cell marker in a variety of cancers, including breast cancer (Ginestier et al. 2007), whereas LU + MPA treatment significantly reduced ALDH ${ }^{\text {bright }}$ activity compared with that observed for MPA treatment alone. LU treatment alone also 


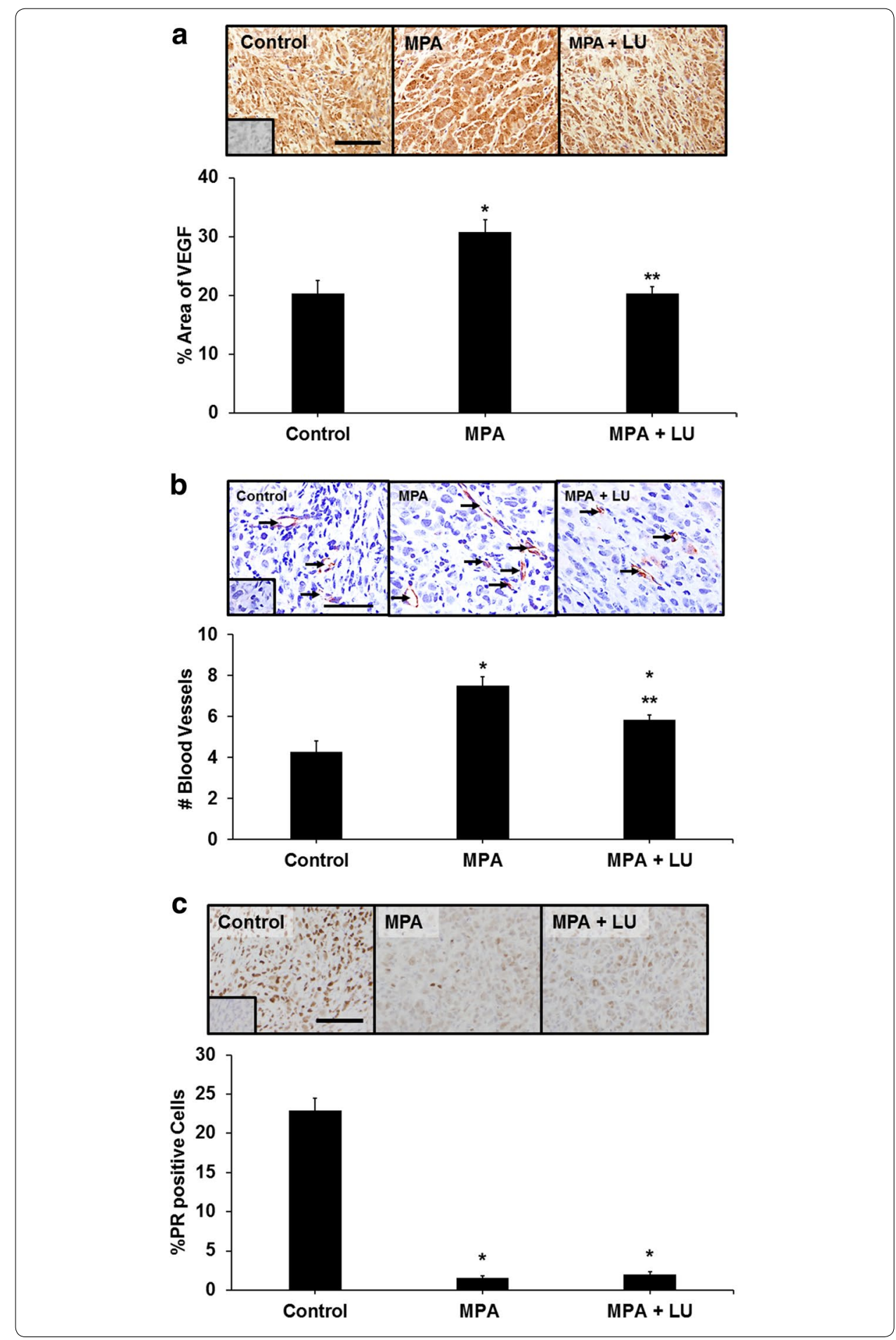

significantly reduced basal ALDH ${ }^{\text {bright }}$ activity (Fig. 7b), suggesting that LU has an inherent ability to reduce the stem cell-like properties of breast cancer cells.

Lastly, mammosphere-formation assays, in which only stem cells with selfrenewal capability are able to seed mammospheres in an anchorage-independent 
(See figure on previous page.)

Fig. 6 Luteolin reduces expression of angiogenesis markers and PR in breast cancer cell xenograft tumors. a Luteolin suppresses MPA-driven VEGF expression in T47-D xenografts. Xenograft tumor-bearing mice were sacrificed at day 79 and tumors collected, processed, and subjected to immunohistochemistry. Upper panel Images represent VEGF (brown) staining from one tumor per group. Scale bar $100 \mu \mathrm{M}$. Lower panel Results represent quantification of VEGF staining (mean \pm SEM percent area of staining) [control (placebo pellet + vehicle), $n=3$ tumors; MPA (MPA pellet + vehicle), $n=7$ tumors; MPA + luteolin (LU) (MPA pellet + LU), $n=8$ tumors]. ${ }^{*}$ Significantly different from control $(P=0.007, A N O V A) .{ }^{*}$ Significantly different from MPA $(P<0.001$; ANOVA). Inset represents no antibody control. b Luteolin suppresses MPA-driven increases in blood-vessel density in T47-D xenografts. Upper panel Images represent CD31 endothelial staining (reddish-brown) of blood vessels from one tumor per group from sections of a $\times 20$ field at captured resolution. Scale bar $50 \mu \mathrm{m}$. Lower panel Results represent quantitation of number of blood vessels stained. Five captures at $\times 20$ were taken per tumor in each group [control (E2 pellet + vehicle), $n=3$ tumors; MPA (MPA pellet + vehicle), $n=7$ tumors; MPA + LU (MPA pellet $+L U), n=8$ tumors]. The number of blood vessels was counted in each tumor capture, averaged for each individual tumor, and the data represent mean number of blood vessels/tumor capture \pm SEM. *Significantly different from control $(P<0.001$, ANOVA). **Significantly different from control and MPA alone ( $P=0.003$, ANOVA followed by a Newman-Keuls multiple comparison test). Inset represents no antibody control. Arrows point to blood vessels represented by CD-31 staining. c Luteolin does not restore MPA-driven loss of PR expression in T47-D xenografts. Upper panel Images represent PR staining from one tumor per group [control (placebo pellet + vehicle), $n=3$ tumors; MPA (MPA pellet + vehicle), $n=7$ tumors; $\mathrm{MPA}+\mathrm{LU}$ (MPA pellet $+\mathrm{LU}), \mathrm{n}=8$ tumors]. Scale bar $100 \mu \mathrm{m}$. Lower panel Results represent quantification of the percent of PR-positively stained cells, means + SEM. *Significantly different from control $[P<0.05$, ANOVA on ranks (Kruskal-Wallis), followed by the Newman-Keuls nonparametric multiple comparisons test]. Inset represents no antibody control

three-dimensional environment (Liu et al. 2005), demonstrated that MPA treatment alone caused a significant increase in the number of mammospheres formed by T47-D cells, an effect that was blunted when cells were treated with MPA + LU. Further, LU treatment alone did not increase the number of mammospheres (Fig. 7c).

\section{Discussion}

A number of recent clinical trials and studies have shown that use of estrogen/progestin combination HRT regimens to alleviate the symptoms of menopause leads to a significantly increased breast cancer risk (Writing Group for the Women's Health Initiative Investigators 2002; MWS Collaborators 2003). Investigators have attempted to understand the role of progestins in this process. Earlier studies from our laboratory have shown that induction of the potently angiogenic VEGF in both T47-D and BT-474 cells is one possible mechanism that might explain increased incidence of breast cancer arising in response to combination HRT (Liang and Hyder 2005; Hyder et al. 1998). Other mechanisms, such as progestin-dependent increases in tumor cell proliferation and development of stem cell-like properties by tumor cells, have also been suggested (Liang and Hyder 2005; Horwitz and Sartorius 2008). Because adjuncts to stem the pro-tumor effects of combination HRT are needed, in the present study we examined the therapeutic ability of the naturally occurring non-toxic flavonoid LU to suppress the growth of and expression of angiogenesis markers in progestin-dependent human breast cancer cell xenograft tumors in vivo, as well as it ability to suppress VEGF induction and the stem cell-like phenotype of breast cancer cells in vitro.

In this study, LU blocked progestin-induced VEGF secretion in both T47-D and BT-474 cells in a similar fashion as apigenin, another naturally occurring flavonoid tested in our laboratory (Mafuvadze et al. 2012). It appears, however, that LU might be a superior pharmacologically active compound to apigenin due to low potential of metabolism 


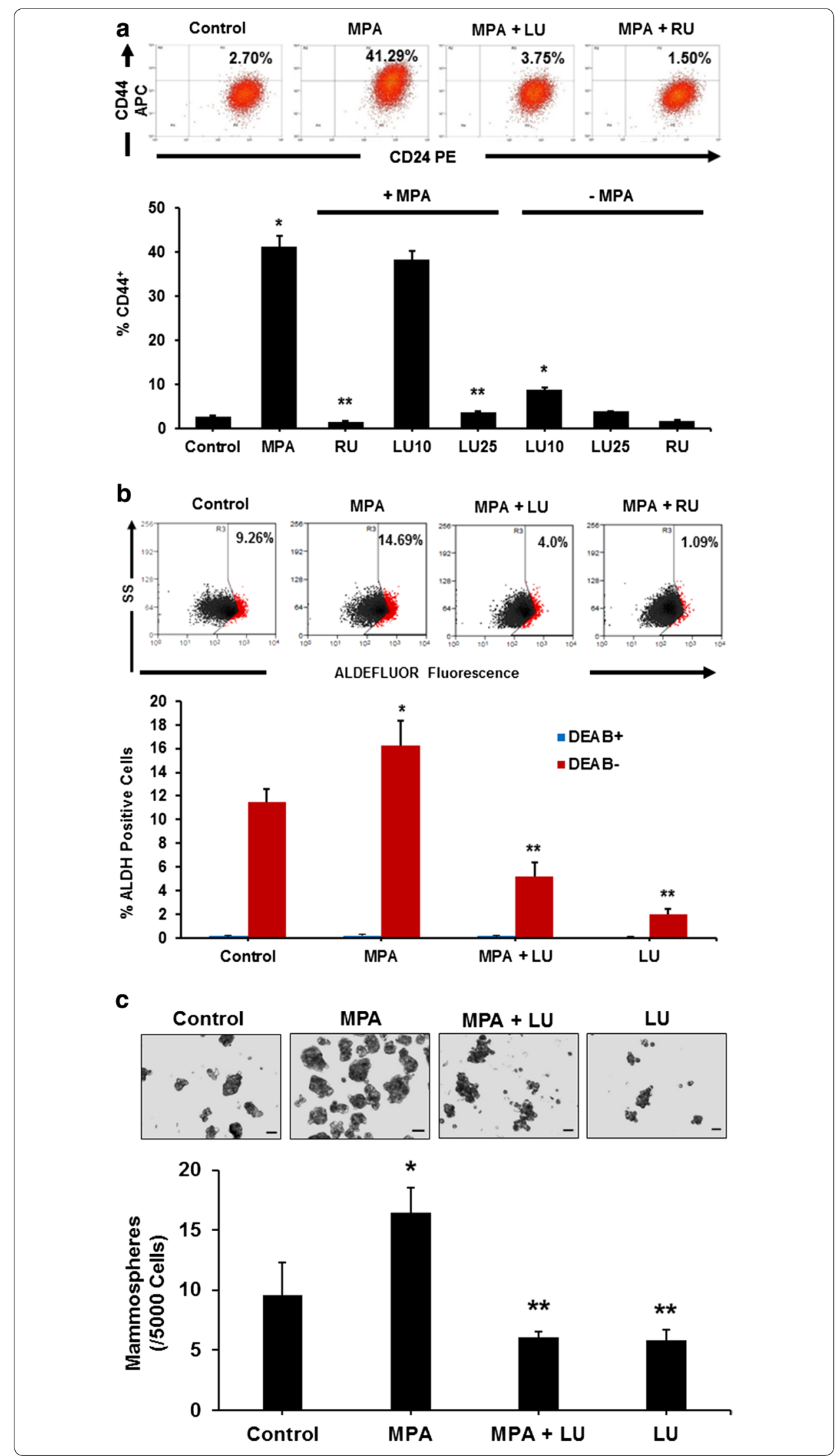


(See figure on previous page.)

Fig. 7 Luteolin suppresses MPA-induced stem cell-like properties of T47-D breast cancer cells. a, b Luteolin suppresses MPA-induced breast cancer cell CD44 expression. T47-D cells were incubated at $37^{\circ} \mathrm{C}$ for $24 \mathrm{~h}$ with $10 \mathrm{nM}$ MPA, 10 or $25 \mu \mathrm{M}$ luteolin (LU), $1 \mu \mathrm{M}$ RU-486 (RU), or $10 \mathrm{nM}$ MPA + $10 \mu \mathrm{M} \mathrm{LU}, 25 \mu \mathrm{M}$, or $1 \mu \mathrm{M}$ RU-486. Following treatment, cells were harvested and labeled with CD44-APC and CD24-PE antibodies and analyzed by FACS. a Upper panel Displays flow cytometry data for control (DMSO only), 10 nM MPA, 10 nM $\mathrm{MPA}+25 \mu \mathrm{M} \mathrm{LU}$, and $10 \mathrm{nM}$ MPA $+1 \mu \mathrm{M}$ RU-486. b Lower panel Quantitative data from three different FACS analysis experiments. Results represent mean $\pm \operatorname{SEM}(n=3)$. *Significantly different from control. **Significantly different from MPA $(P<0.05$, ANOVA). b Luteolin inhibits MPA-induced ALDH bright induction. T47-D cells were treated with $10 \mathrm{nM} \mathrm{MPA} \pm 25 \mu \mathrm{M} \mathrm{LU}$ or $25 \mu \mathrm{M} \mathrm{LU}$ alone at $37^{\circ} \mathrm{C}$ for $24 \mathrm{~h}$. Following treatment, cells were harvested and ALDH activity measured by FACS analysis using the ALDEFLUOR assay. Upper panel Representative flow cytometry data; $\mathrm{ALDH}^{\text {bright }}$ cells are shown in red. The $\mathrm{ALDH}^{\text {bright }}$ gate was set using negative controls $\mathrm{DEAB}+$. Viable cells were gated using Pl; once the gates were set, they were applied throughout the analyses. Lower panel Quantitative data from four different ALDEFLUOR assay experiments. Results represent mean \pm SEM $(n=4)$. *Significantly different from control (DMSO only). **Significantly different from control and MPA ( $P<0.05$, ANOVA followed by a Newman-Keuls multiple comparison test). $c$ Luteolin suppresses MPA-induced breast cancer cell mammosphere formation. T47-D cells were treated at $37^{\circ} \mathrm{C}$ for $48 \mathrm{~h}$ with $10 \mathrm{nM} \mathrm{MPA}, 10 \mathrm{nM} \mathrm{MPA}+25 \mu \mathrm{M}$ LU, or $25 \mu \mathrm{M} \mathrm{LU}$ alone. Following treatment, cells from each group were seeded into six-well plates (5000 cells/well) and treated for seven more days in Complete MammoCult medium. Cells were re-treated with the agent(s) of interest in $1 \mathrm{ml}$ culture medium on days 2 , 4, and 6. Upper panel Representative light microscopic images of T47-D mammospheres formed after 7 days. Scale bar $60 \mu \mathrm{m}$. Lower panel Results represent mean number of mammospheres $\pm \operatorname{SEM}(n=3)$. Number of mammospheres $\geq 60 \mu \mathrm{m}$ was quantitated from 6 to 9 images per well, three wells per group. *Significantly different from control (DMSO only) $(P<0.05)$; **Significantly different from MPA $(P<0.05$, ANOVA on ranks followed by Dunn's method of multiple comparisons)

into potentially toxic compounds (Seelinger et al. 2008). LU blocked VEGF secretion stimulated by both natural and synthetic progestins, including MPA, norgestrel, and norethindrone, all of which are common components of HRT in the United States and Europe. Furthermore, LU suppressed progestin-induced VEGF mRNA expression. Interestingly, LU had no effect on PR at either the mRNA or protein level (data not shown), suggesting that it may interfere with the interaction of PR at PRE on the VEGF promoter (Hyder et al. 2000), or act at a downstream step by modifying co-activators needed for PR-dependent gene transcription (Wu et al. 2004), though these possibilities remain to be tested. LU's ability to block progestin-induced VEGF production in human breast cancer cells could also be due to suppression of the phosphoinositide-3'-kinase pathway (Bagli et al. 2004), or inhibition of the SP-1 transcription factor, both of which are known to control progestin-induced VEGF induction in human breast cancer cells (Wu et al. 2004). These possibilities also remain to be tested.

In T47-D xenografts, LU treatment reduced tumor growth and, in fact, caused tumor regression, likely due to inhibition of MPA-induced VEGF secretion from tumor cells. Because VEGF has also been shown to protect cells from undergoing apoptosis (Liang et al. 2006), loss of VEGF may increase tumor cell apoptosis as well as inhibit angiogenesis. We observed a decrease in the number of tumor blood vessels following LU treatment; however, this reduction in tumor volume was not associated with increased apoptosis or decreased cell proliferation (data not shown), suggesting that neither mechanism is involved in the LU effects on tumor growth.

Luteolin suppressed progestin-mediated increases in stem cell-like properties of breast cancer cells in established assays examining CD44 expression, mammosphere formation, and ALDH ${ }^{\text {bright }}$ activity. Cells that have increased CD44 have been shown to be more aggressive in terms of growth and motility (Al-Hajj et al. 2003), and could be responsible 
for increased tumor growth seen in our established model (Liang et al. 2007). These data suggest that LU reduces the number of cancer stem cell-like cells and/or progenitor cells in progestin-responsive breast cancer and may thereby be able to reverse tumor growth (Liang and Hyder 2005; Horwitz and Sartorius 2008; Cittelly et al. 2013).

\title{
Conclusions
}

In summary, our studies provide evidence that LU has the potential to disrupt angiogenesis and thereby prevent the growth development of progestin-driven tumors. They also provide evidence that LU reduced the MPA-driven cancer stem cell-like and/or progenitor cell subpopulation, strongly suggesting that it exerts its anti-tumor effects in a variety of ways. LU demonstrates significant potential as a new and novel agent that might be used to combat particularly aggressive and hard-to-treat types of breast cancer. It is therefore essential that we further investigate the mechanisms by which LU moderates progestin effects in order to fully exploit its therapeutic potential.

\begin{abstract}
Abbreviations
HRT: hormone replacement therapy; VEGF: vascular endothelial growth factor; PR: progesterone receptor; LU: luteolin; DMSO: dimethyl sulfoxide; MPA: medroxyprogesterone acetate; E2: Estradiol; FBS: fetal bovine serum; DCC: dextrancoated charcoal; SRB: sulforhodamine B; FITC: fluorescein isothiocyanate; PI: propidium iodide; FACS: fluorescenceactivated cell sorting; ELISA: enzyme-linked immunosorbent assay; RT-PCR: reverse transcription-polymerase chain reaction; GAPDH: glyceraldehyde phosphate dehydrogenase; ALDH: aldehyde dehydrogenase; PE: phycoerythrin; APC: allophycocyanin; SEM: standard error of the mean; ANOVA: analysis of variance.
\end{abstract}

\section{Authors' contributions}

MTC participated in the generation of all in vitro and in vivo data, as well as in statistical analysis. YL participated in the in vivo xenograft experiments, in vitro ELISA experiment, and statistical analysis. CBW participated in all the pathology and immunohistochemical data analysis. SG was involved in the stem cell experiments as well as RT-PCR experiments. BM participated in the in vivo studies and in stem cell experiments. SMH conceived of the study, and participated in its design and coordination and helped to draft the manuscript. All authors participated in the initial draft of the manuscript. All authors read and approved the final manuscript.

\section{Author details}

${ }_{1}^{1}$ Department of Biomedical Sciences, University of Missouri, Columbia, MO 65211, USA. ${ }^{2}$ Dalton Cardiovascular Research Center, University of Missouri, 134 Research Park Drive, Columbia, MO 65211, USA. ${ }^{3}$ IDEXX BioResearch, Columbia, MO 65202, USA.

\section{Acknowledgements}

This research was supported by a COR award from the University of Missouri College of Veterinary Medicine, Columbia, MO. SMH is the Zalk Missouri Professor of Tumor Angiogenesis. Funds to purchase the nanodrop instrument were provided through the generosity of numerous donors to the Ellis Fischel Cancer Center.

Compliance with ethical guidelines

Competing interests

The authors declare that they have no competing interests.

Ethical standards

The experiments comply with the current laws of the country in which they were performed (USA).

\section{Ethical approval}

All applicable international, national, and/or institutional guidelines for the care and use of animals were followed. All procedures performed in studies involving animals were in accordance with the ethical standards of the institution or practice at which the studies were conducted.

Received: 11 August 2015 Accepted: 13 August 2015

Published online: 22 August 2015

\section{References}

Al-Hajj M, Wicha MS, Benito-Hernandez A, Morrison SJ, Clarke MF (2003) Prospective identification of tumorigenic breast cancer cells. Proc Natl Acad Sci 100:3983-3988 
Axlund SD, Sartorius CA (2012) Progesterone regulation of stem and progenitor cells in normal and malignant breast. Mol Cell Endocrinol 357:71-79

Bagli E, Stefaniotou M, Morbidelli L, Ziche M, Psillas K, Murphy C, Fotsis T (2004) Luteolin inhibits vascular endothelial growth factor-induced angiogenesis; inhibition of endothelial cell survival and proliferation by targeting phosphatidylinositol 3'-kinase activity. Cancer Res 64:7936-7946

Brisken C (2013) Progesterone signaling in breast cancer: a neglected hormone coming into the limelight. Nat Rev Cancer 13:385-396

Chlebowski RT, Hendrix SL, Langer RD, Stefanick ML, Gass M, Lane DS, Rodabough RJ, Gilligan MA, Cyr MG, Thomson CA, Khandekar J, Petrovitch H, McTieman A (2003) Influence of estrogen plus progestin on breast cancer and mammography in healthy postmenopausal women: the women's health initiative randomized trial. JAMA 289:3243-3253. doi:10.1001/jama.289.24.3243

Chlebowski RT, Kuller LH, Prentice RL, Stefanick ML, Manson JE, Gass M, Aragaki AK, Ockene JK, Lane DS, Sarto GE, Rajkovic A, Schenken R, Hendrix SL, Ravdin PM, Rohan TE, Yasmeen S, Anderson G (2009) Breast cancer after use of estrogen plus progestin in postmenopausal women. N Engl J Med 360:573-587. doi:10.1056/NEJMoa0807684

Cittelly DM, Finlay-Schultz J, Howe EN, Spoelstra NS, Axlund SD, Hendricks P, Jacobsen BM, Sartorius CA, Richer JK (2013) Progestin suppression of miR-29 potentiates dedifferentiation of breast cancer cells via KLF4. Oncogene 32:25552564. doi:10.1038/onc.2012.275

Folkman J (1995) Angiogenesis in cancer, vascular, rheumatoid and other disease. Nat Med 1:27-30

Ginestier C, Hur MH, Charafe-Jauffret E, Monville F, Dutcher J, Brown M, Jacquemier J, Viens P, Kleer CG, Liu S, Schott A, Hayes D, Birnbaum D, Wicha MS, Dontu G (2007) ALDH1 is a marker of normal and malignant human mammary stem cells and a predictor of poor clinical outcome. Cell Stem Cell 1:555-567

Hanahan D, Folkman J (1996) Patterns and emerging mechanisms of the angiogenic switch during tumorigenesis. Cell 86:353-364

Horwitz KB (1992) The molecular biology of RU486. is there a role for antiprogestins in the treatment of breast cancer? Endocr Rev 13:146-163

Horwitz KB, Sartorius CA (2008) Progestins in hormone replacement therapies reactivate cancer stem cells in women with preexisting breast cancers: a hypothesis. J Clin Endocrinol Metab 93:3295-3298

Horwitz KB, Wei LL, Sedlacek SM, d'Arville CN (2013) Progestin action and progesterone receptor structure in human breast cancer: a review. Recent Prog Horm Res 41:249-316

Hyder SM, Murthy L, Stancel GM (1998) Progestin regulation of vascular endothelial growth factor in human breast cancer cells. Cancer Res 58:392-395

Hyder SM, Huang J-C, Nawaz Z, Boettger-Tong H, Mäkelä S, Chiappetta C, Stancel GM (2000) Regulation of vascular endothelial growth factor expression by estrogens and progestins. Environ Health Perspect 108(Suppl 5):785-790

Knutson TP, Lange CA (2014) Tracking progesterone receptor-mediated actions in breast cancer. Pharmacol Ther 142:114-125

Liang Y, Hyder SM (2005) Proliferation of endothelial and tumor epithelial cells by progestin-induced vascular endothelial growth factor from human breast cancer cells: paracrine and autocrine effects. Endocrinology 146:3632-3641

Liang Y, Brekken RA, Hyder SM (2006) Vascular endothelial growth factor induces proliferation of breast cancer cells and inhibits the anti-proliferative activity of anti-hormones. Endocr Relat Cancer 13:905-919

Liang Y, Besch-Williford C, Brekken RA, Hyder SM (2007) Progestin-dependent progression of human breast tumor xenografts: a novel model for evaluating antitumor therapeutics. Cancer Res 67:9929-9936

Liang Y, Benakanakere I, Besch-Williford C, Hyder RS, Ellersieck MR, Hyder SM (2010) Synthetic progestins induce growth and metastasis of BT-474 human breast cancer xenografts in nude mice. Menopause (New York, NY) 17:1040

Liu S, Dontu G, Wicha MS (2005) Mammary stem cells, self-renewal pathways, and carcinogenesis. Breast Cancer Res 7:86

Mafuvadze B, Benakanakere I, Hyder SM (2010) Apigenin blocks induction of vascular endothelial growth factor mRNA and protein in progestin-treated human breast cancer cells. Menopause 17:1055-1063

Mafuvadze B, Liang Y, Besch-Williford C, Zhang X, Hyder SM (2012) Apigenin induces apoptosis and blocks growth of medroxyprogesterone acetate-dependent BT-474 xenograft tumors. Horm Cancer 3:160-171

MWS Collaborators (2003) Breast cancer and hormone-replacement therapy in the Million Women Study. Lancet 362:419-427

Ross RK, Paganini-Hill A, Wan PC, Pike MC (2000) Effect of hormone replacement therapy on breast cancer risk: estrogen versus estrogen plus progestin. J Natl Cancer Inst 92:328-332

Seelinger G, Merfort I, Wölfle U, Schempp CM (2008) Anti-carcinogenic effects of the flavonoid luteolin. Molecules 13:2628-2651

Siegel RL, Miller KD, Jemal A (2015) Cancer statistics, 2015. CA Cancer J Clin 65:5-29

Skehan P, Storeng R, Scudiero D, Monks A, McMahon J, Vistica D, Warren JT, Bokesch H, Kenney S, Boyd MR (1990) New colorimetric cytotoxicity assay for anticancer-drug screening. J Natl Cancer Inst 82:1107-1112

Tsai SA, Stefanick ML, Stafford RS (2011) Trends in menopausal hormone therapy use of US office-based physicians, 2000-2009. Menopause (New York, NY) 18:385

Writing Group for the Women's Health Initiative Investigators (2002) Risks and benefits of estrogen plus progestin in healthy postmenopausal women: principal results from the women's health initiative randomized controlled trial. JAMA 288:321-333. doi:10.1001/jama.288.3.321

Wu J, Richer J, Horwitz KB, Hyder SM (2004) Progestin-dependent induction of vascular endothelial growth factor in human breast cancer cells preferential regulation by progesterone receptor B. Cancer Res 64:2238-2244 